\title{
A digital archive of human activity in the McMurdo Dry Valleys, Antarctica
}

\author{
Adrian Howkins ${ }^{1}$, Stephen M. Chignell ${ }^{2}$, Poppie Gullett ${ }^{3}$, Andrew G. Fountain ${ }^{4,5}$, Melissa Brett ${ }^{4}$, and \\ Evelin Preciado ${ }^{6}$ \\ ${ }^{1}$ Department of History, University of Bristol, Bristol, BS8 1TH, UK \\ ${ }^{2}$ Institute for Resources, Environment and Sustainability, University of British Columbia, \\ Vancouver, British Columbia, V6T 1Z4, Canada \\ ${ }^{3}$ Department of History, Colorado State University, Fort Collins, Colorado, 80523, USA \\ ${ }^{4}$ Department of Geology, Portland State University, Portland, Oregon, 97207, USA \\ ${ }^{5}$ Department of Geography, Portland State University, Portland, Oregon, 97207, USA \\ ${ }^{6}$ Department of Ecosystem Science and Sustainability, Colorado State University, \\ Fort Collins, Colorado, 80523, USA
}

Correspondence: Adrian Howkins (adrian.howkins@bristol.ac.uk)

Received: 5 January 2020 - Discussion started: 23 January 2020

Revised: 21 March 2020 - Accepted: 10 April 2020 - Published: 13 May 2020

\begin{abstract}
Over the last half century, the McMurdo Dry Valleys (MDV) of East Antarctica have become a globally important site for scientific research and environmental monitoring. Historical data can make important contributions to current research activities and environmental management in Antarctica but tend to be widely scattered and difficult to access. We address this need in the MDV by compiling over 5000 historical photographs, sketches, maps, oral interviews, publications, and other archival resources into an online digital archive. The data have been digitized and georeferenced using a standardized metadata structure, which enables intuitive searches and data discovery via an online interface. The ultimate aim of the archive is to create as comprehensive as possible a record of human activity in the MDV to support ongoing research, management, and conservation efforts. This is a valuable tool for scientists seeking to understand the dynamics of change in lakes, glaciers, and other physical systems, as well as humanistic inquiry into the history of the Southern Continent. In addition to providing benchmarks for understanding change over time, the data can help target field sampling for studies working under the assumption of a pristine landscape by enabling researchers to identify the date and extent of past human activities. The full database is accessible via a web browser-based interface hosted by the McMurdo Long Term Ecological Research site: http://mcmurdohistory.lternet.edu/ (last access: 5 May 2020). The complete metadata data for all resources in the database are also available at the Environmental Data Initiative: https://doi.org/10.6073/pasta/6744cb28a544fda827805db123d36557 (Howkins et al., 2019).
\end{abstract}

\section{Introduction}

Antarctica's McMurdo Dry Valleys (MDV) comprise the largest ice-free area in the Southern Continent and are among the coldest and driest places on Earth. Since their discovery in 1903, relatively few people have visited the MDV, and the vast majority of these visitors have been involved in scientific activity. Historical perspectives can make valuable contributions to current scientific research in Antarctica, including the MDV (Howkins, 2016a, b). As a result of the international and often decentralized nature of Antarctic research, historical data are widely scattered and frequently difficult to access. Photographs and field notebooks, for example, often remain with individual researchers. Universities, libraries, archives, and national Antarctic programs have different collection policies and metadata standards, and historical data have only occasionally been digitized and made available on- 
line. More broadly, the future-oriented nature of much scientific research in Antarctica means that preservation of the historical record has often been a low priority.

The aim of this project was to collect historical data related to the MDV, digitize it, and make it easily available to researchers working in the region through an online archive. The dispersed and varied nature of historical documents related to the MDV has necessitated an eclectic approach to data collection. We have concentrated our efforts on data from the United States and New Zealand, the two countries with the most significant scientific programs in the MDV. We have also collected data from other countries with historical interests in the region.

\section{Data}

\subsection{Data collection}

Using bibliographies of MDV publications (including grey literature) (Antarctic Division, D.S.I.R., 1985; Mead, 1978; New Zealand Antarctic Programme, 1995), recommendations from other researchers, and outreach to "Old Antarctic Explorer" organizations, we compiled a list of individuals who have worked in the MDV. We then contacted these individuals with requests for historical photographs and documents related to the MDV (Fig. 1). When we received interested replies, we collected the data using one of the following approaches. If data (especially photographs) were already available in digital format, we arranged for files to be sent to us electronically. When data were not available digitally, we either arranged for the contributors to digitize their documents locally through commercial scanning services, or we visited the researchers in person with a scanner (either a slide scanner or a flatbed scanner depending on the nature of the data). The in-person visits also facilitated oral history interviews with researchers, which we recorded, transcribed, and included in the archive (Fig. 2).

In addition to individuals, we also worked with universities, libraries, archives, and national Antarctic programs. Sometimes data were already easily accessible online, such as the Antarctica New Zealand's digital photograph collection (Antarctica New Zealand, 2017). More often, however, data were only available in non-digital formats, in which case we followed a digitization process similar to our work with the individual researchers. The resolution and provenance of the photographs and other data are variable, but an inclusive approach was taken to maximize the scope of the database. The full database is accessible via a browser-based interface hosted by the McMurdo Long Term Ecological Research site: http://mcmurdohistory.lternet.edu/. The complete metadata for all resources in the database are also available at the Environmental Data Initiative: https://doi.org/10.6073/ pasta/6744cb28a544fda827805db123d36557 (Howkins et al., 2019).

\subsection{Metadata structure}

All data in the archive are organized according to the Dublin Core (DC), an international metadata element set intended to facilitate the discovery of electronic assets (Weibel, 1997; Weibel et al., 1998). The DC is designed to be simple and flexible, and we have tailored its core fields for the specific purposes of the archive. This provides a consistent metadata structure among the various types of resources while maintaining interoperability with other DC databases. The full list of fields and the associated definitions for each type of resource is available in the Supplement (Table S1).

\subsection{Georeferencing}

Although the DC metadata schema includes a "coverage" field for storing geospatial information, the MDV archival data cover a wide range of spatial scales with highly variable locational certainty. We therefore chose to assign each resource a geographic "place"; these range from the scale of individual huts to entire valleys. The majority of these places are associated with a set of existing geospatial vector layers acquired from the MDV Long Term Ecological Research site (Gardner, 2016), which we augmented to include additional features. The layer list includes the following geospatial vectors:

- camps, stations, and huts;

- glaciers;

- lakes and ponds;

- streams (monitored);

- streams (not monitored);

- stream gauges;

- meteorological stations;

- Dry Valleys Drilling Project sites;

- miscellaneous human features;

- miscellaneous natural features.

We decided that places such as valleys or mountain ranges were too general to assign a specific geospatial layer. However, these were still assigned a searchable term in the relational database and may be assigned a geospatial location as additional layers become available. The general bounding coordinates (decimal degrees) for the MDV and the data in the archive are as follows: north (lat -77.504 ), south (lat -77.642), east (long 164.319), west (long 161.111). 

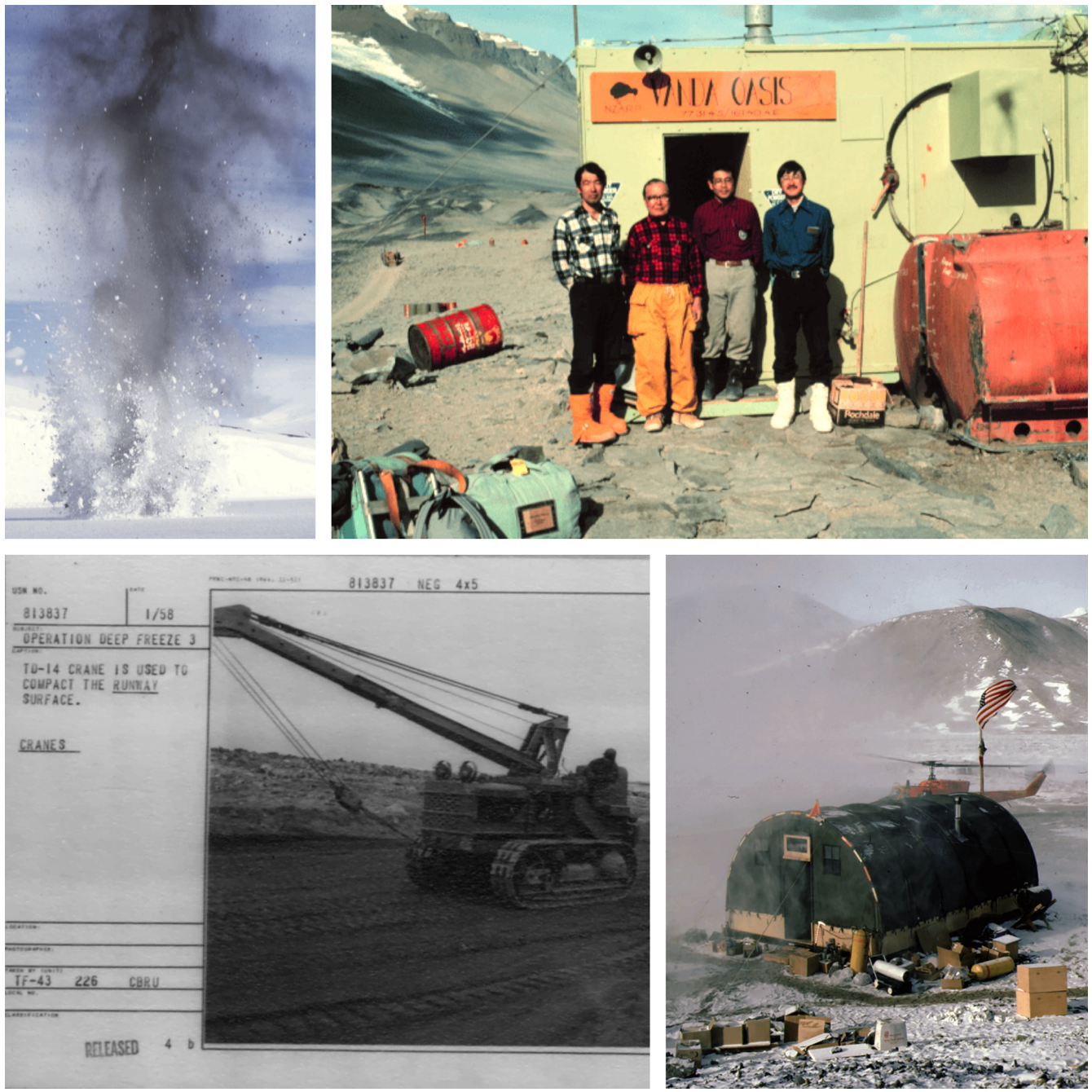

Figure 1. Examples of photographs from the archive showing human activity in the MDV. Unless otherwise stated, copyright for each item remains with the respective contributor. Detailed metadata for each item are available on the archive website (http://mcmurdohistory.lternet. edu) and the Environmental Data Initiative (Howkins et al., 2019).

\section{Online interface}

We developed a web-based interface to facilitate discovery, visualization, and dissemination of the data (Fig. 3). This comprises a relational database built using Drupal, a free and open-source content management system (Buytaert, 2016). The interface provides the ability to quickly filter the database using custom searches or DC metadata elements (e.g., date range, places, people). Clicking a photograph or other resource shows a larger version and the full list of DC metadata elements, which link to related resources. The user can also submit an edit to the metadata, which is intended to engage the Antarctic community and fill information gaps. We also used the geospatial vector layers as the basis for an interactive web app that supports geospatial queries and basic geographic information system functionality.

\section{Data availability}

The historical archive is a "living" dataset that we expect to grow as future contributions are collected and digitized. At the time of writing the database is comprised of more than 5000 archival resources. These include photographs, sketches, interviews (recordings and associated transcripts), maps, sketches, bibliographic citations, and other archival data (e.g., documents) (Fig. 4). All data in the archive are accessible through a userfriendly Drupal website maintained by the McMurdo Dry Valleys Long Term Ecological Research (LTER) project: http://mcmurdohistory.lternet.edu. The complete metadata for all resources in the database are also available at the Environmental Data Initiative: https://doi.org/10.6073/ pasta/6744cb28a544fda827805db123d36557 (Howkins et al., 2019). Future contributions will be uploaded and cata- 
Woke once at $4 \mathrm{am}$; a bit cool at waist. Then not until 8am. C.W. to photo crystals. Deb and I to see moraine heaps. I went on traversing to hill for two miles. Very interesting frost debris (vide Note Book) 3 mosses. Evans found broken Scallops shells.

Note Book) 3 mosses. Evans found broken Scallops shells.
We started 12 noon. We pulled three stages and got to real main Ferrar glacier over a little frozen river: no wind so we tried to light Primus outside for lunch but no go; so put up tent, frozen river: no wind so we tried to light Primus outside for lunch but no go; so put up tent,
found water oozed up at 3 inch cutting in the ice. Tea, cheese, raisins, butter biscuit and chocolate. Charlie and I walked to north. Very find Arabesques in ice; also like walking over Crystal Palace Roof!

Came on five Emperors moulting. Curious squawk, then on to beautiful pinnacle Ice Moraine, next a stream running West, about one foot wide and one inch deep of flowing water, then silt moraine, We arrived under a Curtain glacier. We tossed a coin and Charlie went back to bring camera and Debenham. I walked up and cut steps almost to forty feet ice wall. I saw it was snow. (C.S.W. says like North Wall of Iceberg Tunnel) I returned and found it very slippery. Went up Eastern edge of Curtain and found garnet gneiss. Up to 2200 feet approximately level with cliffs on other side. Here is grey granite with dark dykes. Saw fine panorama. Coo-ed and fine echo.

Down in 3500 paces ( 6 inches each).

Others joined on pinnacle maraine. Ice axe slipt down crevasses; huge icicles. Found sponges and shells on moraine, possible windblown.

Stepped in water about two feet deep, then over glass panes of ice. We got to Emperor Penguins, Stepped in water about two feet deep, then over glass panes of ice. We got to Emperor Penguin, them over like ninepins and they pecked at each other. Flapped angrily; I killed the freshest with ice axe. Pole-axed him; then Evans dragged it to camp. I cleaned him rough and ready with
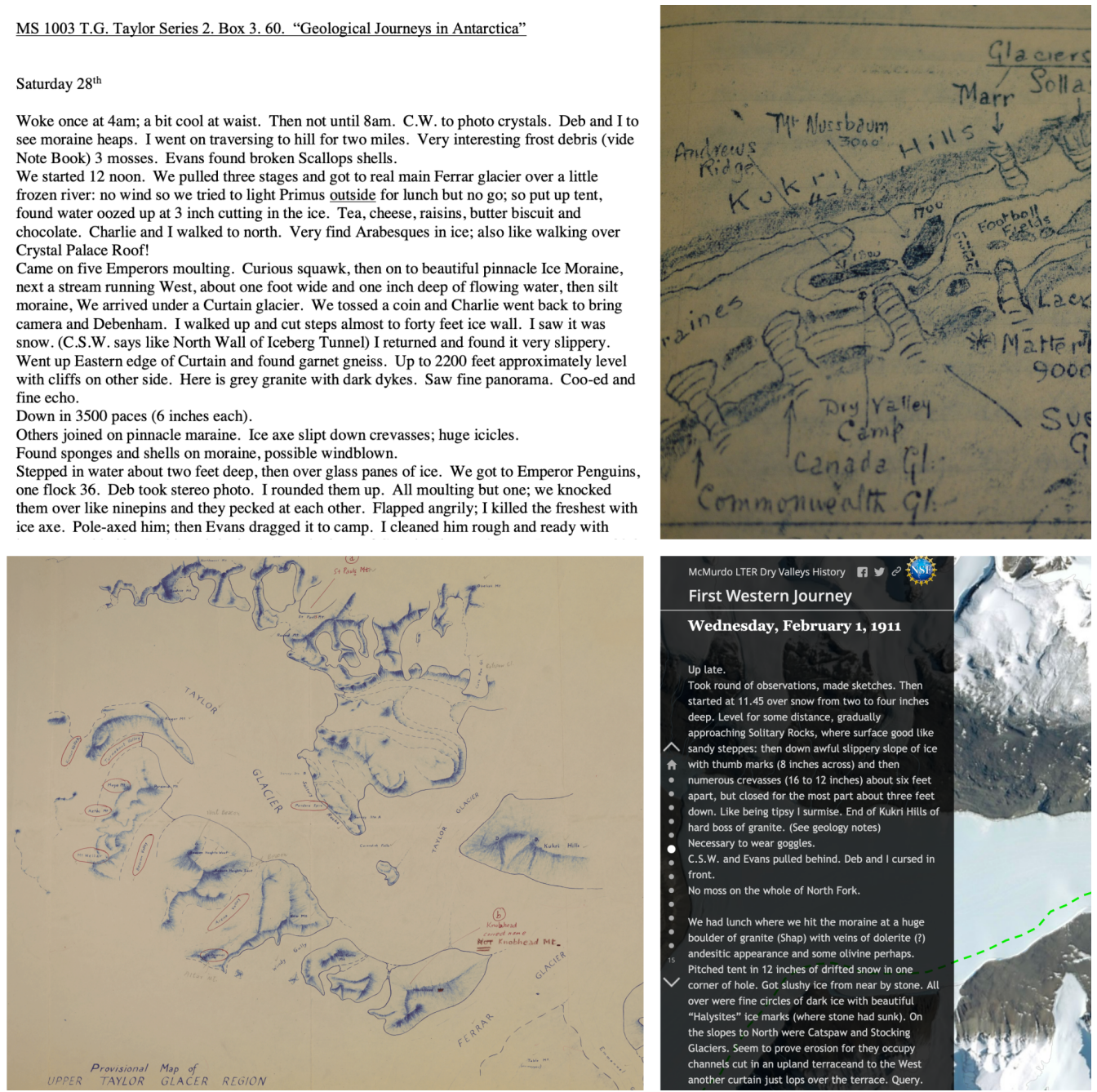

Figure 2. Examples of non-photographic data available in the archive. Unless otherwise stated, copyright for each item remains with the respective contributor. Detailed metadata for each item are available on the archive website (http://mcmurdohistory.lternet.edu) and from the Environmental Data Initiative (Howkins et al., 2019).

loged according to the existing structure. Unless otherwise stated, copyright for each item in the database remains with the respective contributor. For permission to use the material in another venue, the corresponding author or the copyright holder must be contacted directly. Individuals or organizations seeking to make a contribution to the archive are encouraged to contact the corresponding author for information.

\section{Conclusions}

Access to a geospatially referenced, historic account of human activity will be a useful resource to guide current research and environmental management in the MDV. Researchers can use these data to target investigations of the long-term environmental legacy of human activity. Scientists interested in sampling pristine landscapes can search the archive to avoid previously inhabited or impacted areas. The data can also provide benchmarks and insights into function and changes in natural systems (e.g., glacier movement, lake level rise). As research, tourism, and climate change continue to shape the Southern Continent, our database and approach may also serve as a template for other regions seeking to better understand their own human-environmental histories.

Supplement. The supplement related to this article is available online at: https://doi.org/10.5194/essd-12-1117-2020-supplement.

Author contributions. AH and AGF conceived the project. AH, SMC, and PG devised the metadata schema and overarching structure of the database. $\mathrm{AH}$ and SMC led the design of the web map and Drupal interface with assistance from PG, MB, and AGF. MB 


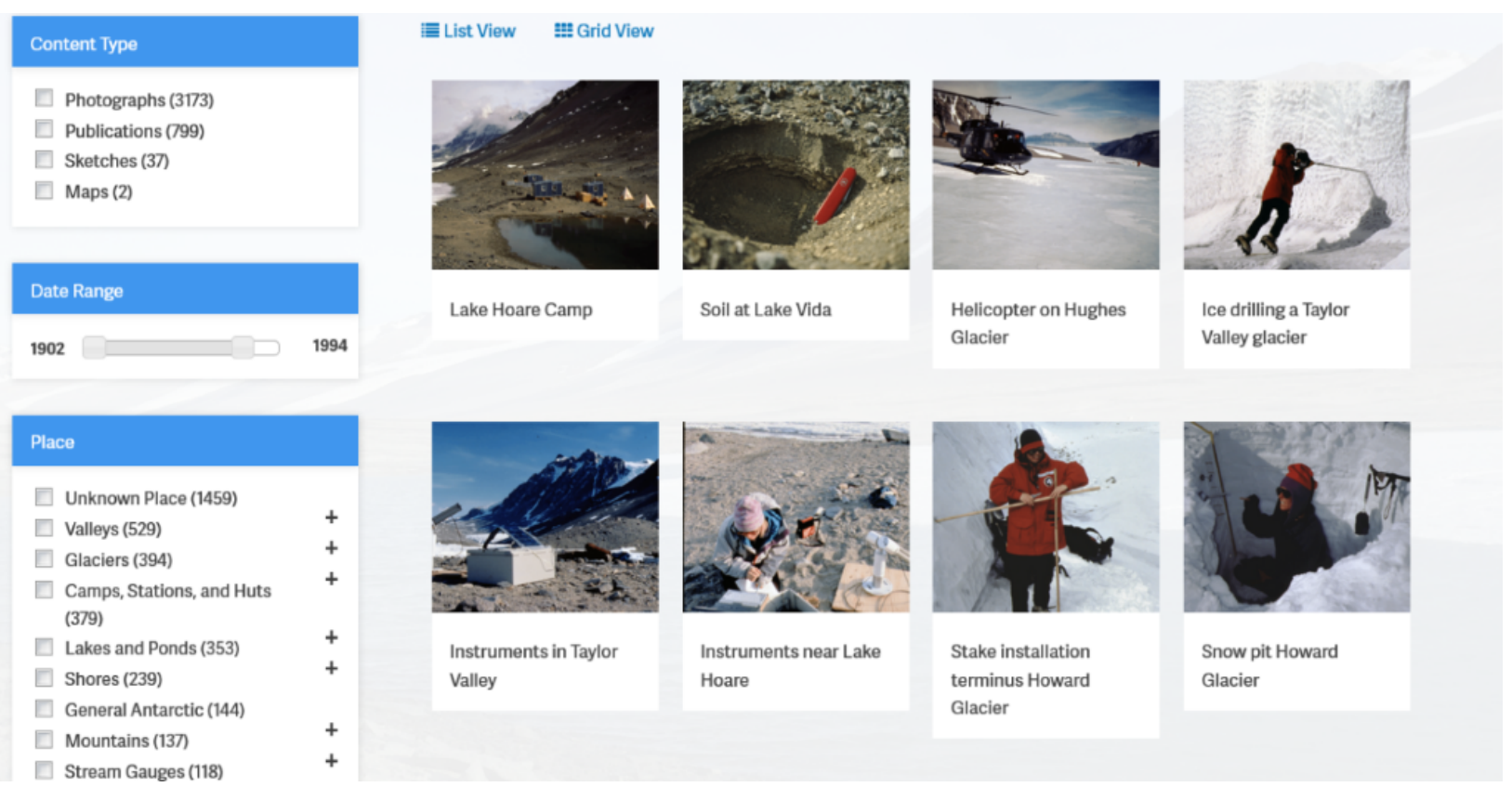

Figure 3. Browser-based interface for searching the archive. The window on the right-hand side refreshes as the filters on the left-hand side are applied. Clicking on a photo or other piece of content opens a new window showing a larger image and the associated metadata.

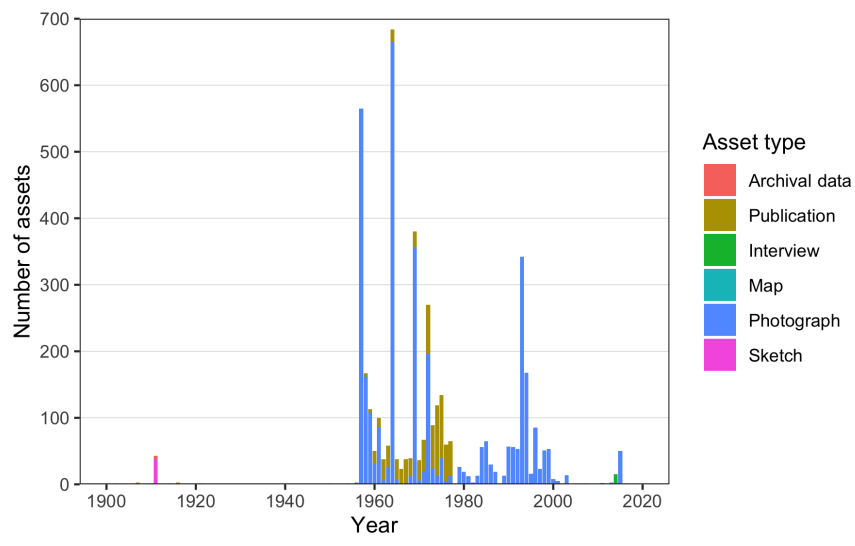

Figure 4. Number of assets in the archive over time, based on their year of creation. Bars are colored by type of asset. Approximately $25 \%$ of the assets (1489 of 5943 total assets) were contributed without information on when they were created (i.e., "unknown season"). These assets are available in the archive but are not shown by this figure. This figure represents a snapshot at the time of writing and will be updated on the website with future additions to the archive.

and AGF led the slide scanning efforts. AH and PG led archival visits and oral history interviews with assistance from AGF and SMC. All authors collected and digitized data for the archive. AH and SMC led the writing of the manuscript, and SMC designed the figures. All authors provided comments and edits for subsequent drafts.
Competing interests. The authors declare that they have no conflict of interest.

Acknowledgements. We are grateful to all of the individuals and organizations that contributed data to the archive. We would like to thank the Morgan Library at Colorado State University, specifically Sophia Linn from the Geospatial Centroid and Mark Shelstad from Archives and Special Collections. We would also like to thank Inigo San Gil, Renée Brown, Cristina Takacs-Vesbach, and Variant Studios, Inc. for their assistance with the Drupal development and website design.

Financial support. This research has been supported by the National Science Foundation, Office of Polar Programs (award no. 1443475).

Review statement. This paper was edited by David Carlson and reviewed by Warwick F. Vincent and one anonymous referee.

\section{References}

Antarctica New Zealand: A.D.A.M. | Antarctica New Zealand Digital Asset Manager, available at: http://antarctica.recollect.co.nz/, last access: 4 October 2017.

Antarctic Division, D.S.I.R.: Bibliography of International Dry Valley Publications Vol. 2, 1978-1984, Bibliography, Antarctic Division, Department of Scientific and Industrial Research, Christchurch, New Zealand, 1985. 
Buytaert, D.: Drupal - Open Source CMS, available at: https: //www.drupal.org/ (last access: 4 October 2017), 2016.

Gardner, C.: McMurdo Dry Valleys Basic GIS Map Layers - up to 2007, https://doi.org/10.6073/pasta/a7f501c8c1065f60fdff481e9fb7c1b0, 2016.

Howkins, A.: Emerging from the Shadow of Science: Challenges and Opportunities for Antarctic History, in Antarctica and the Humanities, Palgrave Macmillan, London, 251-272, 2016 a.

Howkins, A.: Taylor's Valley: What the History of Antarctica's "Heroic Era" Can Contribute to Contemporary Ecological Research in the McMurdo Dry Valleys, Enviro. Hist.-UK, 22, 3-28, https://doi.org/10.3197/096734016X14497391602125, 2016b.

Howkins, A., Chignell, S., Gullett, P., Fountain, A., Brett, M., and Preciado, Evelin: A digital archive of human activity in the McMurdo Dry Valleys, Antarctica from 1902 to present, https: //doi.org/10.6073/pasta/6744cb28a544fda827805db123d36557, 2019.
Mead, K. L.: Bibliography of International Dry Valley Publications, 1907-1977, Bibliography, Antarctic Division, Department of Scientific and Industrial Research, Christchurch, New Zealand, 1978.

New Zealand Antarctic Programme: Bibliography of International Dry Valley Publications, Vol. 3, 1985-1994, Bibliography, New Zealand Antarctic Programme, Christchurch, New Zealand, 1995.

Weibel, S.: The Dublin Core: A Simple Content Description Model for Electronic Resources, Bulletin of the American Society for Information Science and Technology, 24, 9-11, https://doi.org/10.1002/bult.70, 1997.

Weibel, S., Kunze, J., Lagoze, C., and Wolf, M.: Dublin Core Metadata for Resource Discovery, available at: https://www.rfc-editor. org/info/rfc2413 (last access: 19 September 2017), 1998. 